\author{
Military Technical College \\ Kobry El-Kobbah, \\ Cairo, Egypt
}

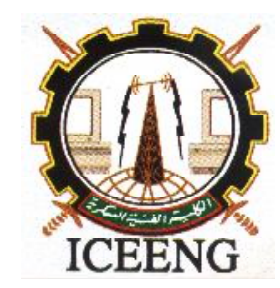

\title{
Parameters Estimations for Storage Unit based on Performance Characteristics
}

\author{
$9^{\text {th }}$ International Conference \\ on Electrical Engineering \\ ICEENG 2014
}

$$
\text { By }
$$

\begin{abstract}
Adel El Shahat*
\section{Abstract:}

Storage systems are needed to provide electricity during the night or on cloudy days to meet the load requirements. Lead-acid batteries are so important even in grid connected applications storage to improve system reliability. So, this is paper aims to address a new method of Electrical Parameters Estimations for this type of storage devices based on Performance Characteristics with the aid of Artificial Neural Network (ANN). To help designers, researchers and users in pointing the direction for indigenous research in electricity storage technologies. First, the parameters of the battery model are identified depending on curve fitting with the aid of improved Thevenin battery model, and the model is validated with a $12 \mathrm{~V}$, 4Ah lead-acid battery Yuasa NP4-12 Battery. The model parameters and characteristics are well depicted in the form of 3D figures. Second, the ANN technique is used to estimate Thevenin Electric Model' parameters in the form of ANN models with their algebraic equations. The proposed outputs for the models are: Discharging Resistance, Shunt Resistance, Back e.m.f. and Charging Resistance; each one is deduced with Battery Characteristics as inputs for every previous outputs: Charging/Discharging Rate, State of Charge, Time, Voltage, and Current. ANN models are created with suitable numbers of layers and neurons, which trained, simulated, checked and their algebraic equations are concluded accurately with excellent regression constant for all almost 1.
\end{abstract}

Keywords: Parameters, Lead-acid battery, model, neural network, and estimation.

* Engineering Science Department, Faculty of Petroleum \& Mining Engineering, Suez University, Egypt 


\section{Introduction:}

The Storage systems are needed to provide electricity during the night or on cloudy days to meet the load requirements. This is usually achieved by using diesel generators as back-up to the PV systems or providing storage systems; mainly lead-acid batteries. Moreover, it is so important that even in grid connected applications storage is sometimes provided to improve system reliability. Lead acid batteries were invented in 1859 by Gaston Planté and first demonstrated to the French Academy of Sciences in 1860. About a century and half after its invention it remains a dominant market product and though regarded as a mature technology, it still has extensive research work being undertaken on it to improve performance and reduce size as well as cost. Though the basic chemistry remains the same there has been a number of variations that have been engineered to meet specific needs and solve identified problems [1] - [5]. The electroactive (The species that directly participate in the chemical reaction that generates electricity) materials in lead acid batteries are:

- $\quad$ Lead oxide $(\mathrm{PbO} 2)$ positive plate (cathode)

- $\quad$ Pure spongy lead $(\mathrm{Pb})$ negative plate (anode)

- Dilute sulphuric acid (H2SO4) electrolyte

In the electrolyte (aqueous solution of sulphuric acid) of a lead-acid battery, three reactions are at work:

$$
\begin{aligned}
\mathrm{H}_{2} \mathrm{O} \leftrightarrow \mathrm{H}^{+}+\mathrm{OH}^{-} \\
\mathrm{H}_{2} \mathrm{SO}_{4} \leftrightarrow 2 \mathrm{H}^{+}+\mathrm{SO}_{4}{ }^{2-} \\
\mathrm{H}_{2} \mathrm{SO}_{4} \leftrightarrow \mathrm{H}^{+}+\mathrm{HSO}_{4}{ }^{-}
\end{aligned}
$$

At the (lead and lead oxide) electrodes, the reactions are:

$$
\begin{gathered}
\text { Negative electrode: } \mathrm{Pb}+\mathrm{SO}_{4}{ }^{2-} \leftrightarrow \mathrm{PbSO}_{4}+2 \mathrm{e}^{-} \\
\text {Positive electrode: } \mathrm{PbO}_{2}+\mathrm{SO}_{4}{ }^{2-}+4 \mathrm{H}^{+}+2 \mathrm{e}^{-} \leftrightarrow \mathrm{PbSO} 4+2 \mathrm{H}_{2} \mathrm{O}
\end{gathered}
$$

The overall reaction is Change in Gibb's free energy $\mathrm{G}$

$$
\begin{gathered}
\mathrm{PbO}_{2}+\mathrm{SO}_{4}{ }^{2-}+4 \mathrm{H}++\mathrm{Pb} \rightarrow 2 \mathrm{PbSO}_{4}+2 \mathrm{H}_{2} \mathrm{O} \\
\text { Change in Gibb's free energy G: } \\
\mathrm{G}=\Sigma \mathrm{G} \text { (Products) }-\Sigma \text { G(Reactants) }
\end{gathered}
$$

The Gibbs free energy (at standard conditions) for the overall cell reaction and this corresponds to the maximum energy that the reaction will release and the computation of $\mathrm{G}$ was obtained from Reid C. E [6]. At both electrodes, lead sulphate is formed, from lead oxide at the positive electrode and from lead itself at the negative electrode [7].At discharge, lead dioxide in positive plates and spongy lead in negative plates react with sulphuric acid in the electrolyte and gradually transform into lead sulphate, during which the sulphuric acid concentration decreases. Conversely, when the battery is recharged, the positive and negative active materials which had been turned into lead sulphate gradually revert to lead dioxide and spongy lead respectively, releasing the sulphuric acid absorbed in the active materials, during which the sulphuric acid concentration increases [8]. A typical lead acid battery with some details of construction 
is shown in Fig. 1.

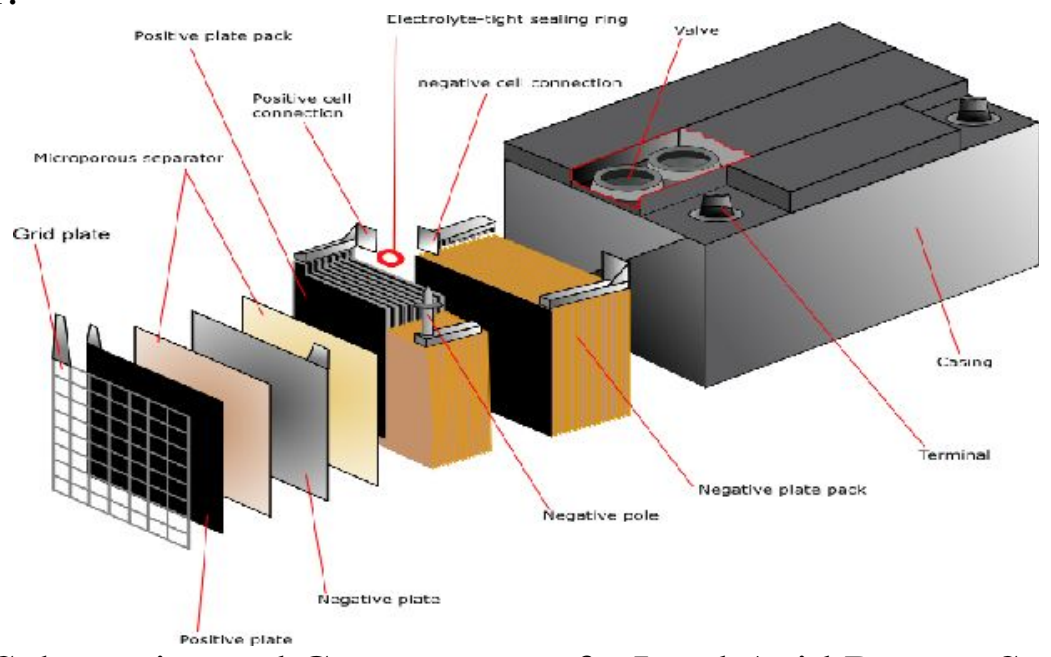

Fig. 1. Schematics and Components of a Lead Acid Battery Source [9]

In practice, the electrodes are alloyed with small amounts of antimony to increase mechanical strength of the soft lead. This however also tends to increase the selfdischarge rate of the batteries (The self-discharge rate is the rate at which the battery loses stored charge under no-load conditions). Some batteries use calcium to enhance plate resistance to corrosion and reduce self-discharge [10], [11]. Modeling of storage system battery is very important topic in many applications from various aspects like the paper here. New flexible and efficient modeling method for electrochemical systems based on lead-acid batteries taking advantage of analogies with familiar concepts in physics of semiconductors and electrical engineering is presented [12]. Batteries' models and state of charge monitoring procedures are evaluated [13], monitoring procedures are intended for a more effective State Of Charge (SOC) computing. Analytical models have been developed to diminish test procedures for product realization with the aid of advanced simulation tools to become more accurately model battery systems which will reduce the time and cost required for product realization. A Neural network based learning system method has been proposed for estimation of residual capacity of lead acid battery [14]. State of Charge (SOC) of a storage battery gives the capacity remaining in the battery to meet the load demands. SOC of a Lead Acid battery is predicted based on the temperature compensated value of electrolytes' specific gravity (Sp. gr.). Open Circuit Voltage (OCV) is used as the parameter to predict the SOC [15]. To optimize fuel economy, an accurate estimation of the battery state of charge (SOC) during vehicle operation is required. SOC estimation for lead-acid batteries is particularly difficult due to side reactions and losses during charging, particularly at high SOC. To estimate the battery SOC, an equivalent-circuit lead-acid battery model is used to simulate the battery dynamics. This model incorporates losses associated with top charging which can affect the battery SOC estimation. In addition, parameter 
estimation techniques are utilized to identify the dynamic model parameters [16].

\section{Lead-Acid Battery Model}

The various battery models reported in [17]- [18], and [19] are reviewed and the dynamic model of the lead-acid battery proposed by Jantharamin $N$. and Zhang, $L$. in [20] is used. The simplest battery model uses a simple resistor connected in series with an ideal voltage source [17], [20], but it is inconvenient and unrealistic. Another model reported in [21] is the Thevenin battery model. This model includes a parallel resistorcapacitor network, in addition to the voltage source (connected in series with a resistor, to model overvoltage effects within the battery. However, again all model parameters are considered constant, and hence this model is inaccurate. A further improvement in the Thevenin battery model is proposed in [18], as shown in Fig. 2. The battery emf is represented by the voltage across the capacitor $C_{b}$. The shunt resistor $R_{s d}$ models selfdischarge losses in the battery. The ohmic voltage drop and overvoltage effect are modeled by separate resistors as shown.

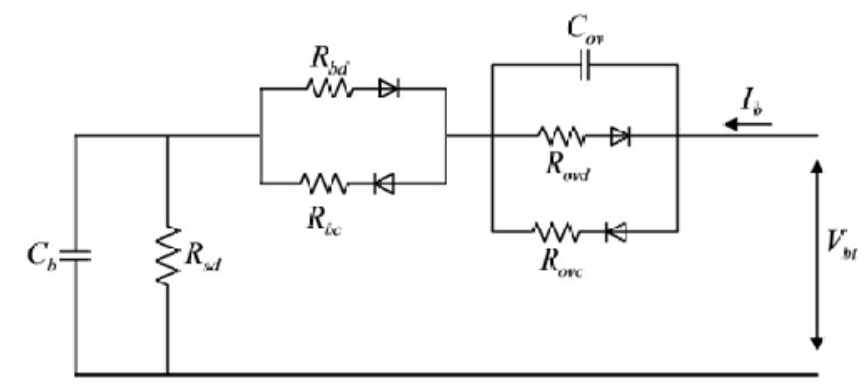

Fig. 2. Improved Thevenin Battery Model

During charging, the current flows through the ohmic resistance $\mathrm{R}_{\mathrm{bc}}$ and overvoltage resistance $R_{\text {ovc }}$ and when the battery is discharging, the current flows through $R_{b d}$ and $\mathrm{R}_{\text {ovd. }}$. Ideal diodes are connected in their respective paths to allow the current flowing through the desired resistances. All values of the model parameters are a function of the battery emf. However, in practice, the ohmic voltage drop and overvoltage effects can be identified together and polarization resistance can be described by a single equivalent resistance for each operating mode, which makes the battery model compact [18]-[19].

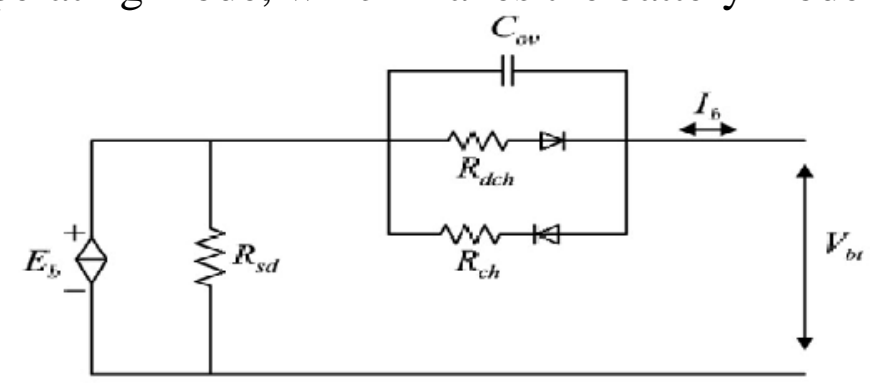

Fig. 3. Dynamic Model of A Lead-Acid Battery 
Fig. 3. shows the dynamic model of lead-acid proposed by Jantharamin $N$. and Zhang, $L$. in [20] which is the modified one of the model shown in Fig. 2. The ohmic voltage drop and overvoltage effects are identified together and polarization resistance is described by a single equivalent resistor $R_{c h}$ or $R_{d c h}$ for each operating mode [20]. The charge stored in the battery can be given as an integral of battery current $I_{b}$ [17]. The parameters of the battery model are identified using curve fitting techniques, and the model is validated with a $12 \mathrm{~V}, 4$ Ah Yuasa (NP4-12) battery [20]-[22] for all discharge rates. The discharge characteristics of the battery are studied using the battery model, then Neural Model is adopted for more generality to help any user, designer or researchers and to make benefits from this technique advantages. The battery emf, $\mathrm{E}_{b}$, is modeled by a dependent voltage source as shown in Fig. 3. The battery emf is a linear function of the SOC (state of charge) of the battery. In lead-acid batteries, there exist a difference between the battery emf $\mathrm{E}_{\mathrm{b}}$, and terminal voltage of the battery $\mathrm{V}_{\mathrm{bt}}$, known as polarization effect. This polarization effect, caused due to the ohmic voltage drop and overvoltage effects, in the lead-acid battery is modeled by a resistor-capacitor network, as shown in Fig. 3. The polarization resistance is represented by a single equivalent resistor $R_{c h}$ or $R_{d c h}$ for an each operating mode [20]. During the charging process, the current flows through the ohmic resistor $\mathbf{R}_{\mathrm{ch}}$, while, during discharging process, the current flows through ohmic resistor $\mathrm{R}_{\mathrm{dch}}$. Ideal diodes are connected in their respective paths to allow the current flowing through the desired resistances. The self-discharge losses in the battery are modeled by the resistor $R_{\mathrm{sd}}$. The battery current is denoted by $\mathrm{I}_{\mathrm{b}}$.

The terminal voltage of the battery during the charging mode and discharging mode can be given by (4) and (5), respectively [20]:

$$
\begin{aligned}
& \mathrm{V}_{\mathrm{bt} \_ \text {charging }}=\mathrm{E}_{\mathrm{b}}+\mathrm{I}_{\mathrm{b}} \mathrm{R}_{\mathrm{ch}}\left(1-\exp \left(-\mathrm{t} /\left(\mathrm{R}_{\mathrm{ch}} \mathrm{C}_{\mathrm{ov}}\right)\right)\right) \\
& \mathrm{V}_{\mathrm{bt} \text { discharging }}=\mathrm{E}_{\mathrm{b}}-\mathrm{I}_{\mathrm{b}} \mathrm{R}_{\mathrm{dch}}\left(1-\exp \left(-\mathrm{t} /\left(\mathrm{R}_{\mathrm{dch}} \mathrm{C}_{\mathrm{ov}}\right)\right)\right)
\end{aligned}
$$

During the charge and discharge cycles, the dynamic characteristics of the battery depend on the battery SOC, the charge/discharge rate, and the electrolyte temperature [20]. The model parameters are identified to determine the battery terminal voltage during charging and discharging process, the parameter identification process proposed by Jantharamin N. and Zhang, L. in [20] is implemented in this paper. The model parameters are determined using curve-fitting technique, and using the manufacturer's datasheet for the Yuasa (NP4-12) battery, rated $4 \mathrm{Ah}, 12 \mathrm{~V}$ [20]-[22]. Based on the Yuasa (NP4-12) battery manufacturer's datasheet for, the relationship between the battery open circuit voltage and remaining battery capacity is approximately linear, as shown in Fig. 4 [22]. Using the linear approximation technique, a function between $E_{b}$ and SOC is deduced as [20]:

$$
\mathrm{E}_{\mathrm{b}}=0.01375(\mathrm{SOC})+11.5
$$




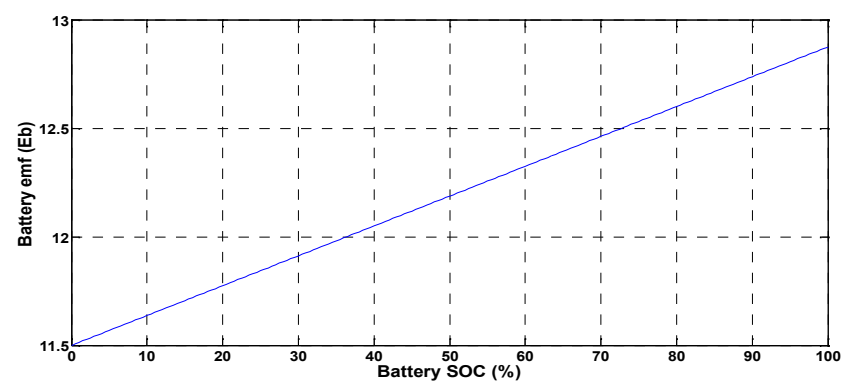

Fig. 4. Variation in $\mathrm{E}_{\mathrm{b}}$ as a Function of the Battery SOC

The information on the remaining battery capacity against the storage time in the manufacturer's datasheet for the Yuasa (NP4-12) battery is used to model the selfdischarge resistance [22]. The values of $\mathrm{R}_{\mathrm{sd}}$ are plotted against the SOC, [20] as shown in Fig. 5, and using curve-fitting method, to get a quadratic polynomial function as in (7), to simulate the variation of self-discharge resistance $\mathrm{R}_{\mathrm{sd}}$ of a battery as a function of the battery SOC in $\mathrm{k} \Omega$.

$$
\mathrm{R}_{\mathrm{sd}}=-0.039(\mathrm{SOC})^{2}+4.27(\mathrm{SOC})-19.23
$$

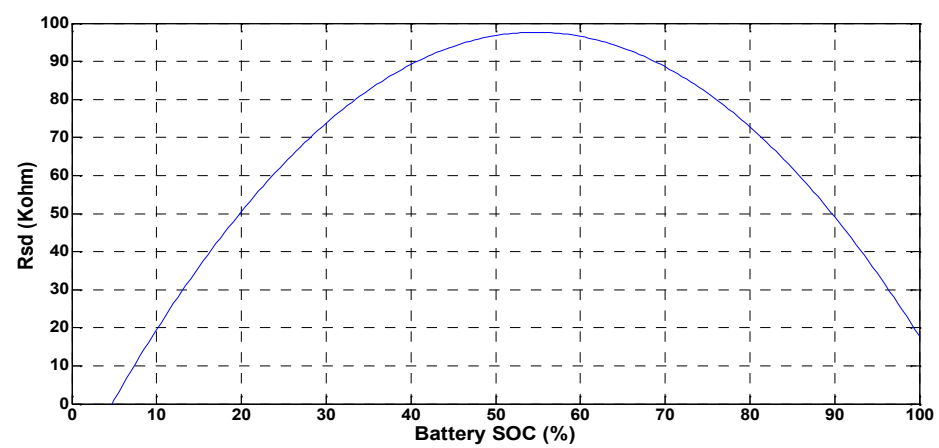

Fig. 5. Variation in $\mathrm{R}_{\mathrm{sd}}$ as a Function of the Battery SOC

The resistance Rdch (Discharge Polarization Resistance) can be divided into two components as [20]:

$$
\mathrm{R}_{\mathrm{dch}}=\mathrm{R}_{\mathrm{bdi}}+\mathrm{R}_{\mathrm{bd}}
$$

The resistance $\mathrm{R}_{\mathrm{bdi}}$, models the change in the terminal voltage from the battery emf during transient interval, and hence, depends on the discharge current. The resistance $\mathrm{R}_{\mathrm{bd}}$, models the variation of $\mathrm{R}_{\mathrm{dch}}$, with the battery SOC as the discharge proceeds [20]. The mathematical expression in a form of two exponential functions represent $R_{b d i}$ and given as [20]:

$$
R_{b d i}=1.01 \exp \left(-2.21 \mathrm{I}_{\mathrm{b}}\right)+0.24 \exp \left(-0.06 \mathrm{I}_{\mathrm{b}}\right)
$$




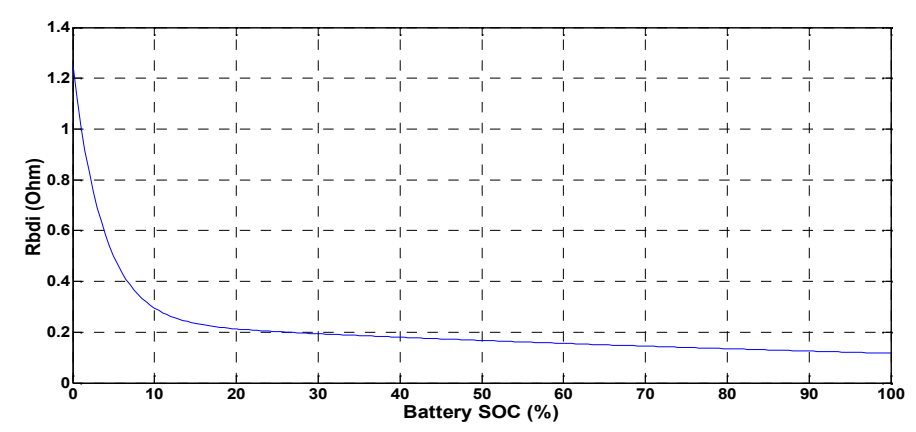

Fig. 6. Variation in $\mathrm{R}_{\mathrm{bdi}}$ with the Battery SOC

After transients die away, the resistance $R_{b d}$ for specific discharge rate can be derived as a mathematical function using the curve fitting technique [20] and established for $\mathrm{R}_{\mathrm{bd}}$ as:

$$
\mathrm{R}_{\mathrm{bd}}=2.926 \exp (-0.042 \mathrm{SOC})
$$

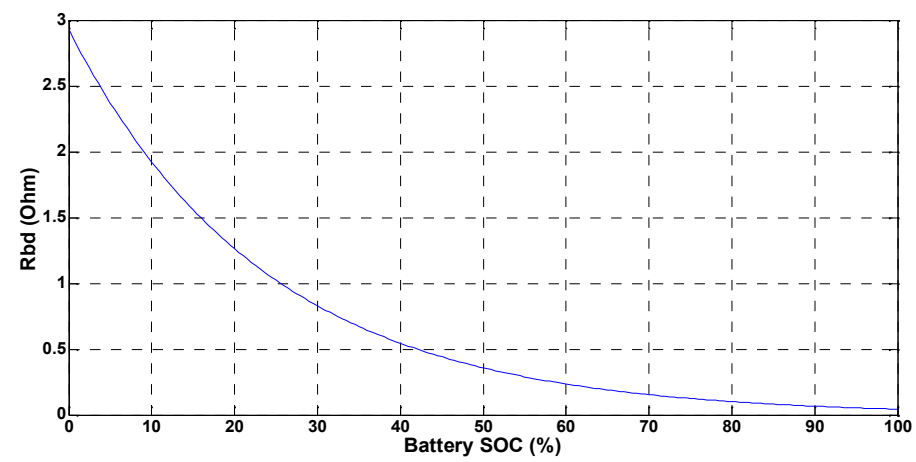

Fig. 7. Variation in $\mathrm{R}_{\mathrm{bd}}$ with the Battery SOC

From the discharge characteristics of the Yuasa NP4-12 battery, it can be seen that the lower discharge rate curves have longer transient interval [20]-[22]. So, the capacitance is estimated according to the lowest discharge rate given in the data sheet. As a result, for this battery, the overvoltage capacitance $\mathrm{C}_{\mathrm{ov}}$ is obtained to be $40 \mathrm{~F}$ [20]. Resistance $\mathrm{R}_{\mathrm{ch}}$ during the charging process can be divided into two components as [20]:

$$
\mathrm{R}_{\mathrm{ch}}=\mathrm{R}_{\mathrm{bci}}+\mathrm{R}_{\mathrm{bc}}
$$

The resistance $R_{b c i}$ models the change in the terminal voltage from the battery emf during the transient interval, and hence, depends on the charging rate. The resistance $R_{b c}$ models the variation of the internal resistance with the battery SOC. The resistance $\mathrm{R}_{\mathrm{bci}}$ can be estimated as in [20] with approximation to the value of 5 . After transients die way, the resistance $R_{b c}$ can be expressed as in [20], using the curve fitting technique to describe this variation with the battery SOC is given as [20]:

$$
\mathrm{R}_{\mathrm{bc}}=9.32 * 10^{-5}(\mathrm{SOC})^{2}+0.01(\mathrm{SOC})+0.028
$$




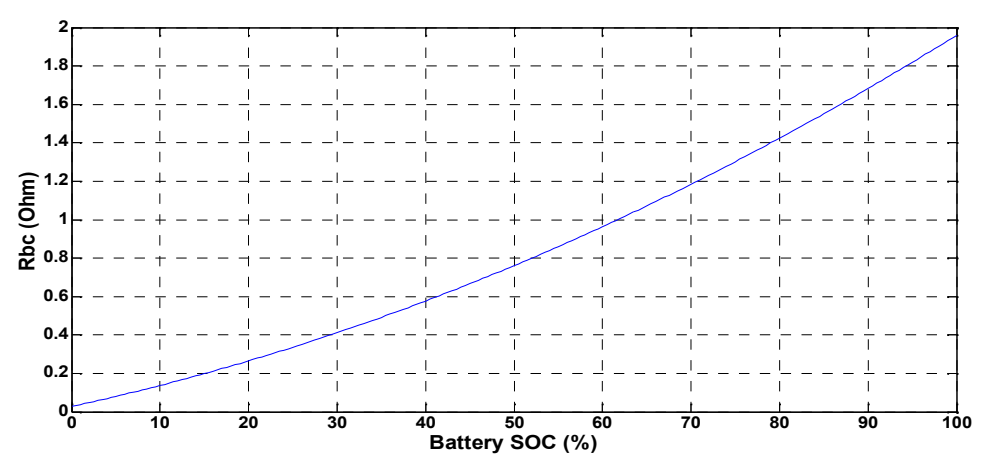

Fig. 8. Variation in $\mathrm{R}_{\mathrm{bc}}$ with the Battery SOC

The battery model is validated by simulating it for all discharge rates: $0.05,0.1,0.2$, $0.4,0.6,1,2$ and $3 \mathrm{CA}$. The terminal voltage $\mathrm{V}_{\mathrm{bt}}$ of the model is obtained in each case. This terminal voltage $\mathrm{V}_{\mathrm{bt}}$ of the battery model is then compared with the discharge characteristics given in the manufacturing data sheet of the $12 \mathrm{~V}, 4$ Ah Yuasa battery [22] as shown in Fig. 9. The validation results are shown in Fig. 10. Comparison shows a nearly close match between them with little difference.

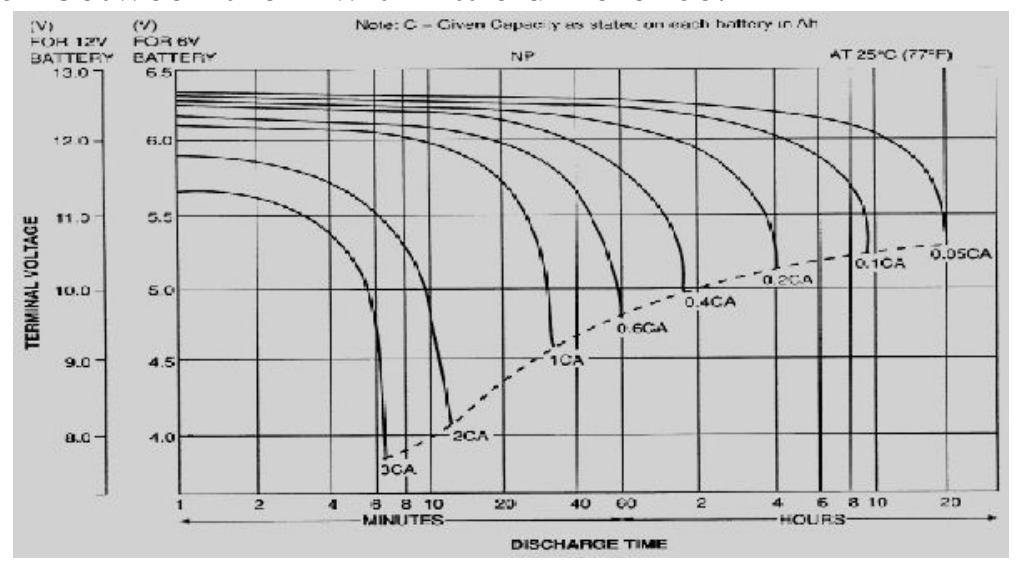

Fig. 9. Discharge Characteristics of Yuasa NP4-12 Battery (From the manufacturer's data sheet) [22]

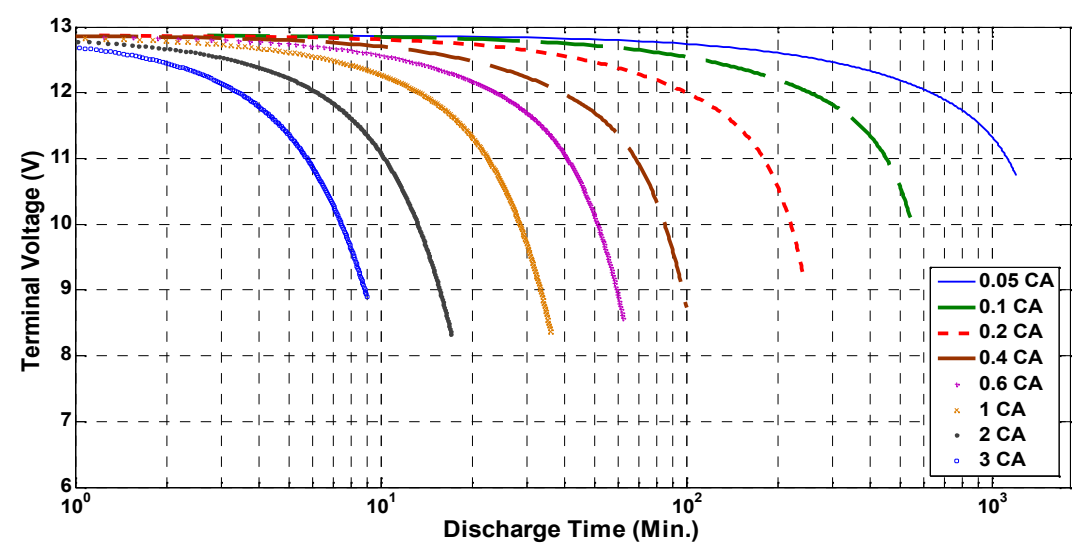

Fig. 10. Validation Results of the Battery Model 


\section{Artificial Neural Network Modeling}

Using the Artificial Neural Network (ANN), with back-probagation technique which used, described and verified before in the field of renewable energy and power like in [23-32] for the author, in implementing ANN models to estimate Thevenin Electric Model' parameters with their algebraic equations. These ANN models' outputs are: Discharging Resistance $\mathrm{R}_{\mathrm{dch}}$, Shunt Resistance $\mathrm{R}_{\mathrm{sd}}$, Back e.m.f. $\mathrm{E}_{\mathrm{b}}$ and Charging Resistance $R_{c h}$; each one is deduced with Battery Characteristics as inputs for every previous outputs: Charging/Discharging Rate, State of Charge, Time, Voltage, and Current. ANN models are created with suitable numbers of layers and neurons, which trained, simulated, checked and their algebraic equations are concluded accurately with excellent regression constant for all almost 1. This is done to make benefits from the ability of neural network of interpolation between points and also curves. Finally, the algebraic equations are deduced to use it without training the neural unit in each time. These models have a suitable number of layers and neurons in each layer as shown in the following to suit their job with precise manner and distinguished regression constant. Moreover, ANN models have the ability to deal with all curves (data) as surface or mapping face as shown in the coming figures. The training data for various characteristics is well depicted in the following 3D figures for all inputs and targets (outputs).

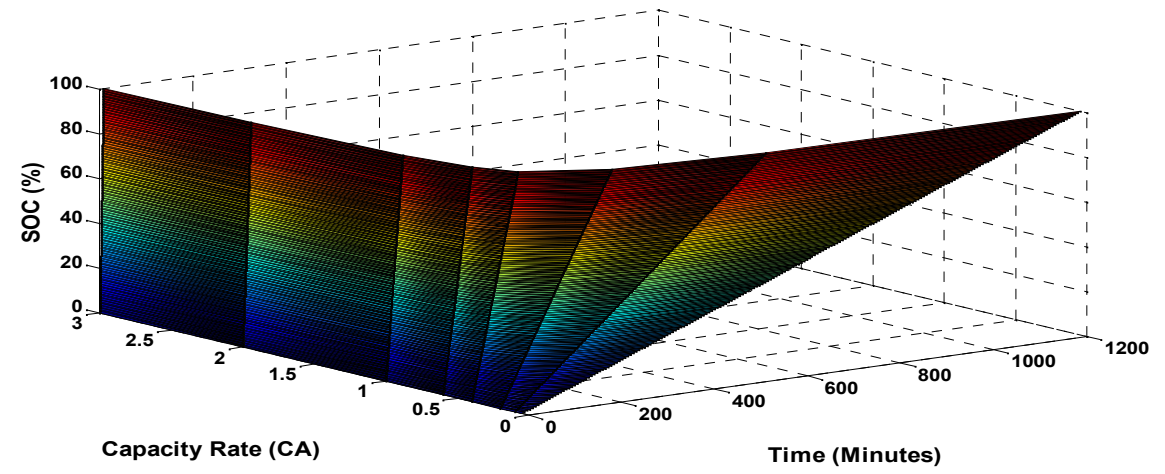

Fig. 11. 3D relation for SOC, CA with time

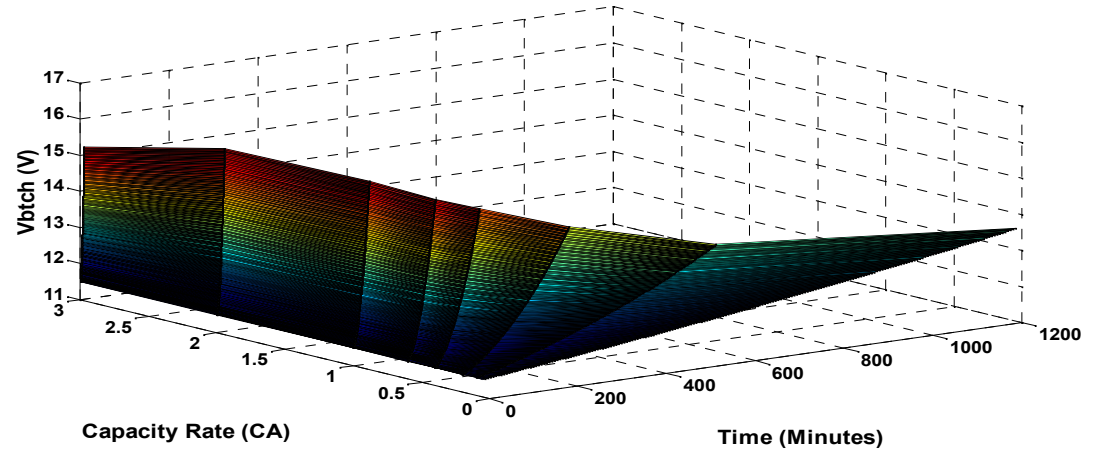

Fig. 12. 3D relation for $\mathrm{V}_{\mathrm{btch}}$, $\mathrm{CA}$ with time 


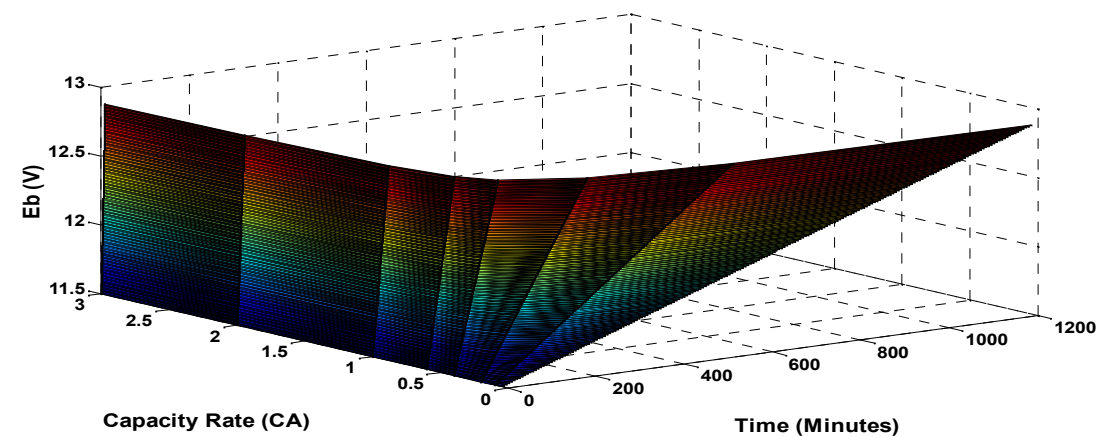

Fig. 13. 3D relation for $E_{b}, C A$ with time

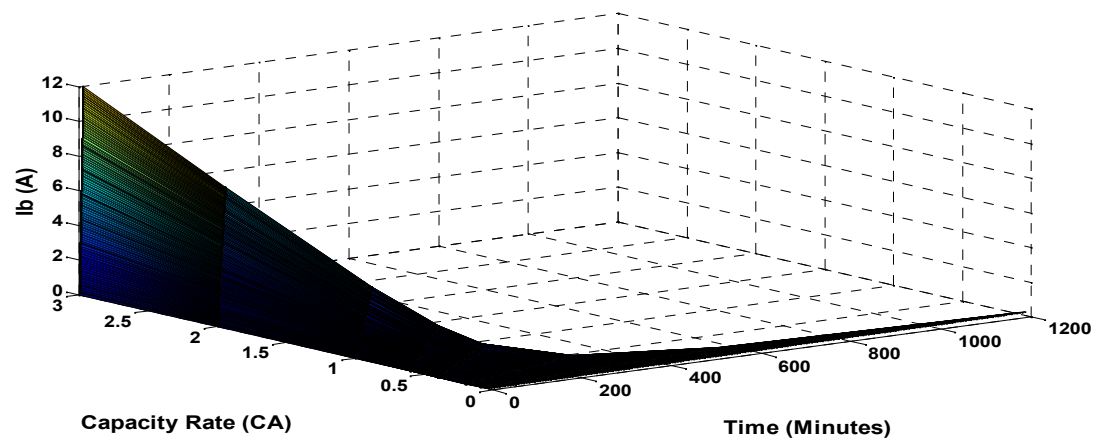

Fig. 14. 3D relation for $\mathrm{I}_{\mathrm{b}}, \mathrm{CA}$ with time

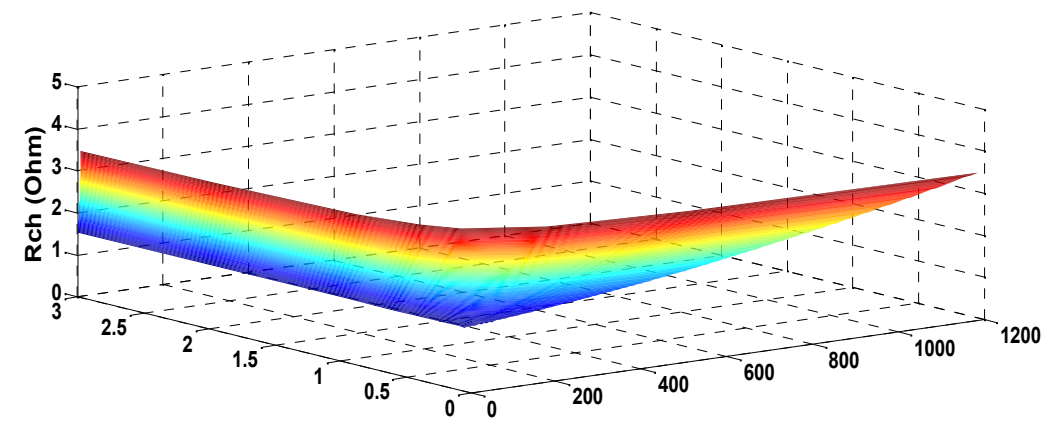

Capacity Rate (CA)

Time (Minutes)

Fig. 15. 3D relation for $\mathrm{R}_{\mathrm{ch}}, \mathrm{CA}$ with time

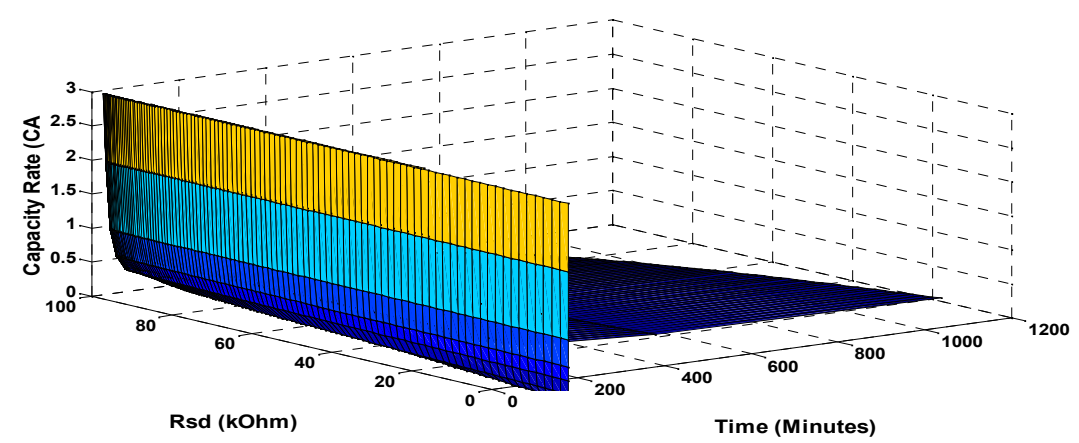

Fig. 16. 3D relation for $R_{\text {sd }}$, $C A$ with time 


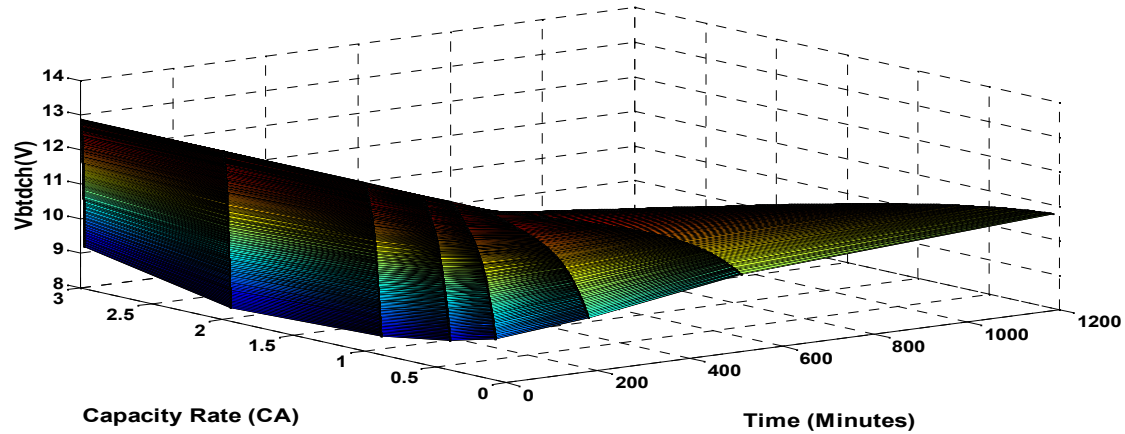

Fig. 17. 3D relation for $\mathrm{V}_{\mathrm{btdch}}$, $\mathrm{CA}$ with time

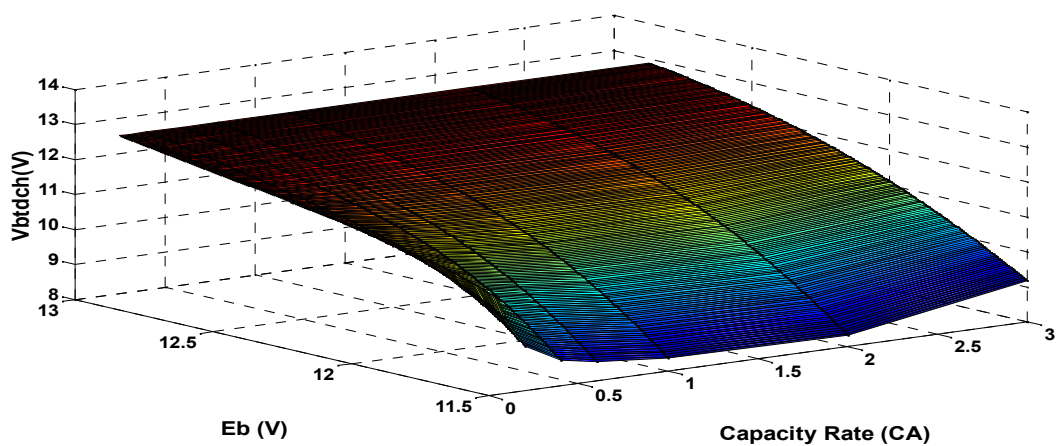

Fig. 18. 3D relation for $\mathrm{V}_{\mathrm{btdch}}, \mathrm{E}_{\mathrm{b}}$, with $\mathrm{CA}$

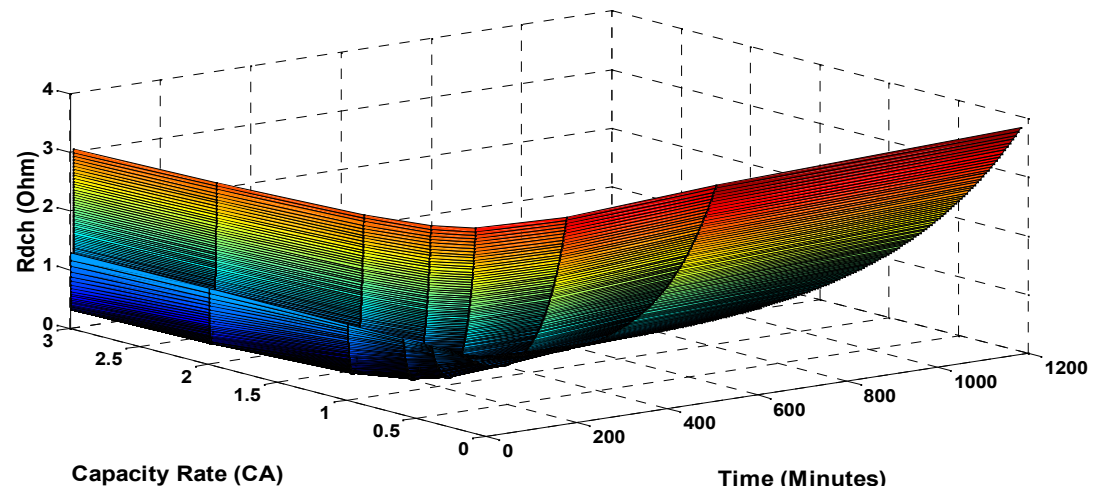

Fig. 19. 3D relation for $\mathrm{R}_{\mathrm{dch}}$, $C A$ with time

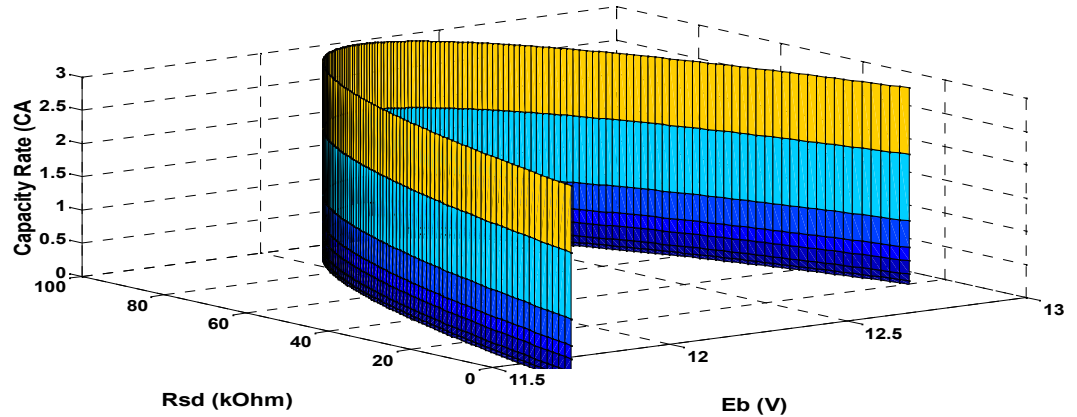

Fig. 20. 3D relation for $R_{s d}$, $C A$ with $E_{b}$ 


\subsection{Discharging Resistance $\boldsymbol{R}_{\text {dch }}$ Model}

The first model output is: Discharging Resistance $\mathrm{R}_{\mathrm{dch}}$ range, with ranges of Battery Characteristics as inputs: Capacity Rate CA, State of Charge SOC, Time, Voltage

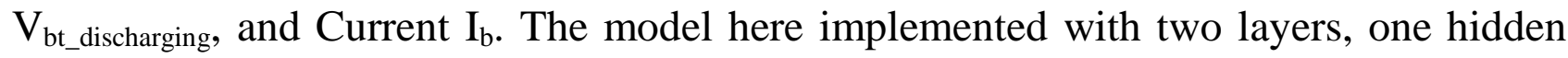
with $\log$-sig function and 2 neurons; second layer is with pure-line function with 1 neuron. Comparisons between the output and target, Performance, Training state, and Regression for $1^{\text {st }}$ Model are presented to show the validity of the model.

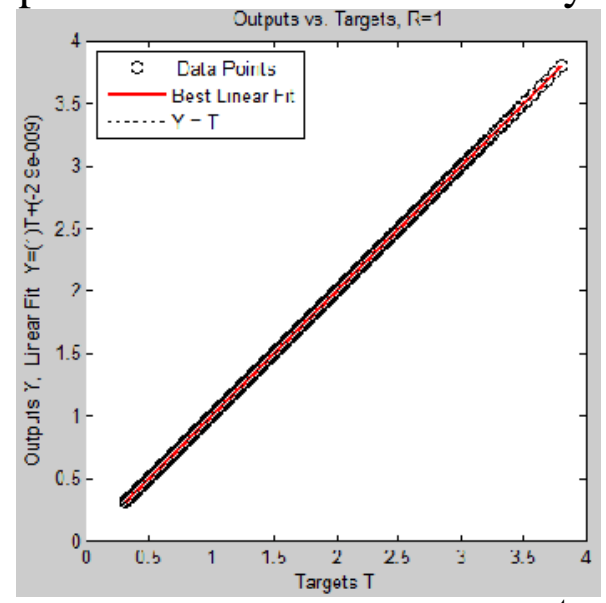

Fig. 21. Output VS Target for $1^{\text {st }}$ Model

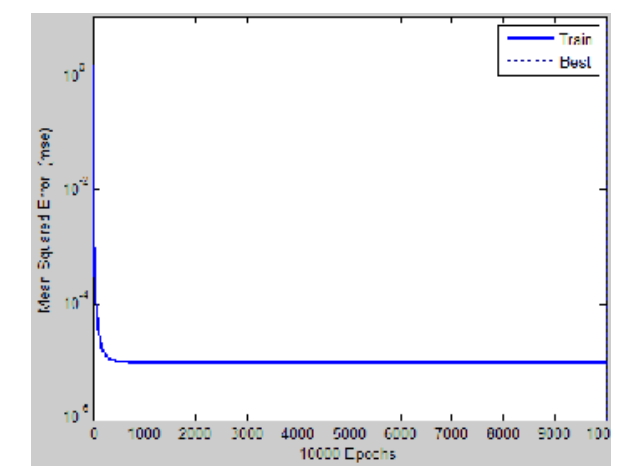

Fig. 22. Performance for $1^{\text {st }}$ Model

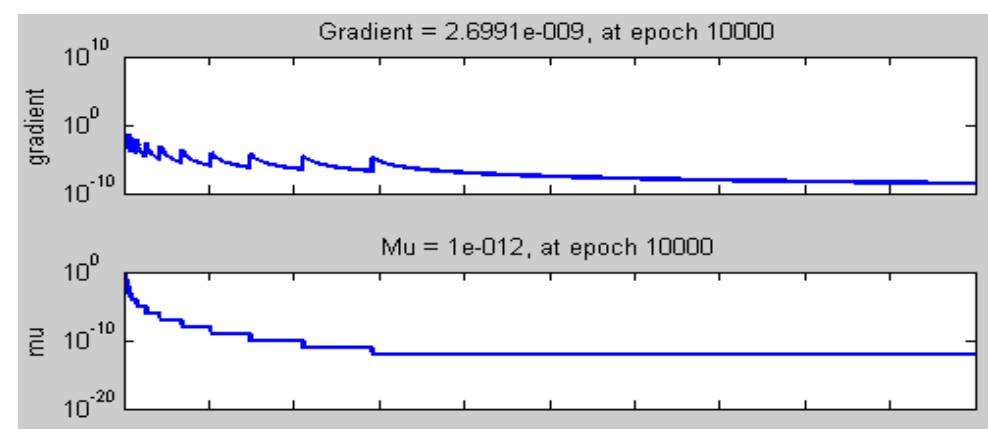

Fig. 23. Training state for $1^{\text {st }}$ Model 


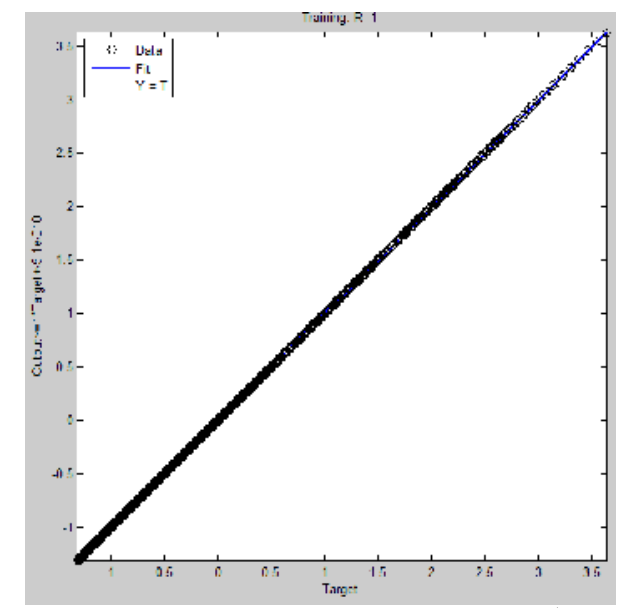

Fig. 24. Regression $(\mathrm{R}=1)$ for $1^{\text {st }}$ Model

The model algebraic equation is deduced as the following:

$$
\begin{aligned}
& \mathrm{CA}_{\mathrm{n}}=(\mathrm{CA}-0.9188) /(0.9890) \\
& \text { Time }_{\mathrm{n}}=(\text { Time }-137.6875) /(237.6148) \\
& \mathrm{SOC}_{\mathrm{n}}=(\mathrm{SOC}-50.0000) /(29.0205) \\
& \mathrm{V}_{\text {bdchn }}=\left(\mathrm{V}_{\text {btdch }}-11.5007\right) /(1.0980) \\
& \mathrm{I}_{\mathrm{bn}}=\left(\mathrm{I}_{\mathrm{b}}-1.8375\right) /(2.5233)
\end{aligned}
$$

The previous Equations present the normalized inputs (subscript $\mathrm{n}$ denotes normalized variable) for the ANN model and the following equations lead to the required derived output equation.

$$
\begin{aligned}
\mathrm{E} 1 & =0.0948 \mathrm{CA}_{\mathrm{n}}+0.0014 \mathrm{Time}_{\mathrm{n}}+1.2282 \mathrm{SOC}_{\mathrm{n}}-0.0046 \mathrm{~V}_{\mathrm{btdchn}}-0.0525 \mathrm{I}_{\mathrm{bn}}+6.6795 \\
\mathrm{~F} 1 & =1 /(1+\exp (-\mathrm{E} 1)) \\
\mathrm{E} 2=0.0027 \mathrm{CA}_{\mathrm{n}} & +0.0018 \mathrm{Time}_{\mathrm{n}}-0.0074 \mathrm{SOC}_{\mathrm{n}}+0.0317 \mathrm{~V}_{\mathrm{btdchn}}-5.4241 \mathrm{I}_{\mathrm{bn}}-14.4143 \\
\mathrm{~F} 2 & =1 /(1+\exp (-\mathrm{E} 2)) \\
\mathrm{R}_{\mathrm{disCH}} & =1.0 \mathrm{e}+004(-0.0386 \mathrm{~F} 1+4.9496 \mathrm{~F} 2)+384.2665
\end{aligned}
$$

The un- normalized out put

$$
\mathrm{R}_{\mathrm{disCH}}=0.7085 \mathrm{R}_{\mathrm{disCHn}}+1.2383
$$

\subsection{Shunt Resistance $\boldsymbol{R}_{s d}$ Model}

The second model output is: Shunt Resistance $\mathrm{R}_{\text {sd }}$ range, with ranges of Battery Characteristics as inputs: Capacity Rate CA, State of Charge SOC, Time, Voltage

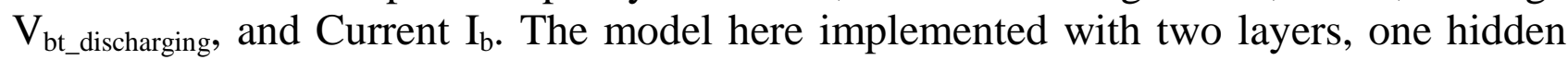
with log-sig function and 2 neurons; second layer is with pure-line function with 1 neuron. Comparisons between the output and target, Performance, Training state, and Regression for $2^{\text {nd }}$ Model are presented to show the validity of the model. 


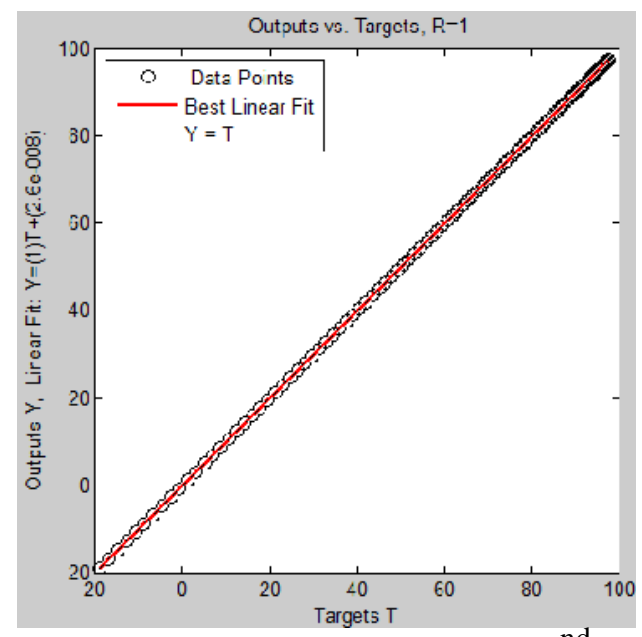

Fig. 25. Output VS Target for $2^{\text {nd }}$ Model

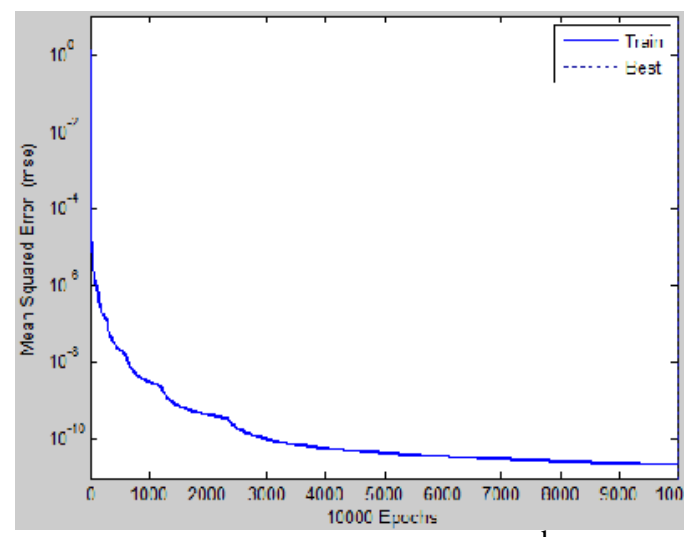

Fig. 26. Performance for $2^{\text {nd }}$ Model

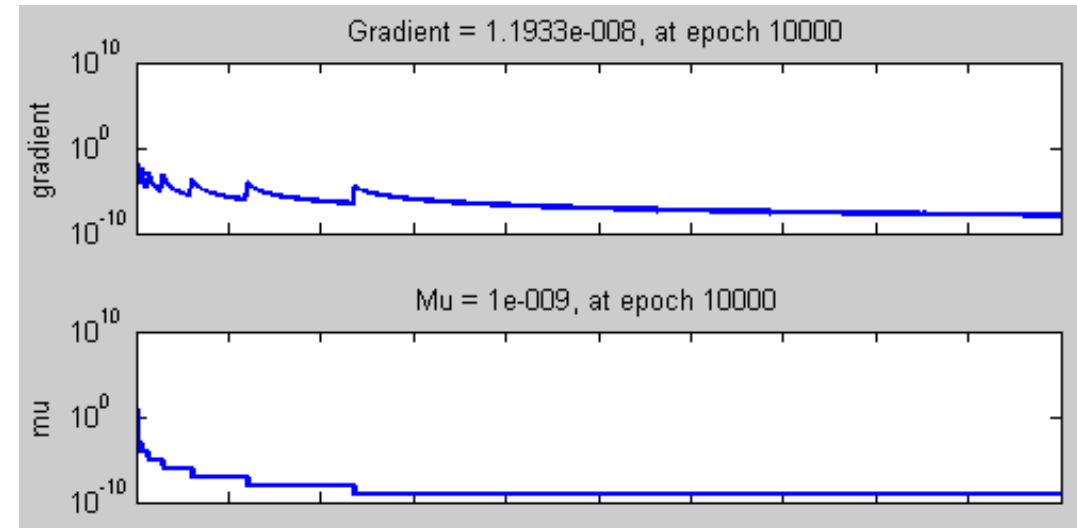

Fig. 27. Training state for $2^{\text {nd }}$ Model 


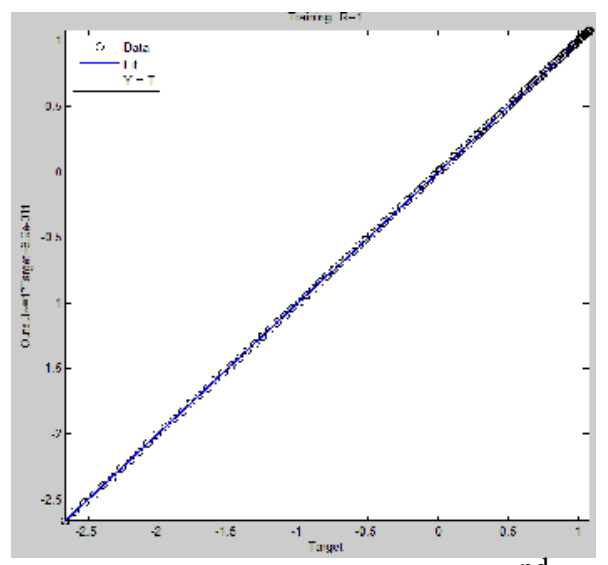

Fig. 28. Regression $(\mathrm{R}=1)$ for $2^{\text {nd }}$ Model

The model algebraic equation is deduced as the following:

$$
\begin{gathered}
\mathrm{E} 1=-0.0003 \mathrm{CA}_{\mathrm{n}}-0.00004 \mathrm{Time}_{\mathrm{n}}-0.8645 \mathrm{SOC}_{\mathrm{n}}+0.0001 \mathrm{~V}_{\mathrm{btdchn}}+0.0002 \mathrm{I}_{\mathrm{bn}}-2.4236 \\
\mathrm{~F} 1=1 /(1+\exp (-\mathrm{E} 1)) \\
\mathrm{E} 2=0.00004 \mathrm{CA}_{\mathrm{n}}+0.0002 \text { Time }_{\mathrm{n}}+0.9388 \mathrm{SOC}_{\mathrm{n}}-0.0012 \mathrm{~V}_{\mathrm{btdchn}}+0.0001 \mathrm{I}_{\mathrm{bn}}-2.5500 \\
\mathrm{~F} 2=1 /(1+\exp (-\mathrm{E} 2)) \\
\mathrm{R}_{\mathrm{sdn}}=-23.8845 \mathrm{~F} 1-19.0662 \mathrm{~F} 2+4.3730
\end{gathered}
$$

The un- normalized out put

$$
\mathrm{R}_{\mathrm{sd}}=31.2690 \mathrm{R}_{\mathrm{sdn}}+63.9450
$$

\subsection{Back e.m.f. $E_{b}$ Model}

The third model output is: Back e.m.f. $\mathrm{E}_{\mathrm{b}}$ range, with ranges of Battery Characteristics as inputs: Capacity Rate CA, State of Charge SOC, Time, Voltage

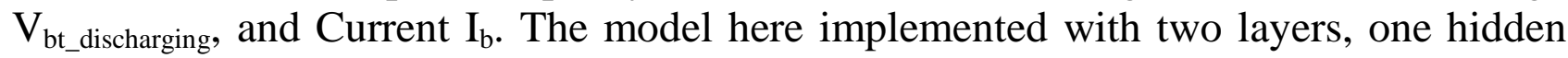
with $\log$-sig function and 3 neurons; second layer is with pure-line function with 1 neuron. Comparisons between the output and target, Performance, Training state, and Regression for $3^{\text {rd }}$ Model are presented to show the validity of the model.

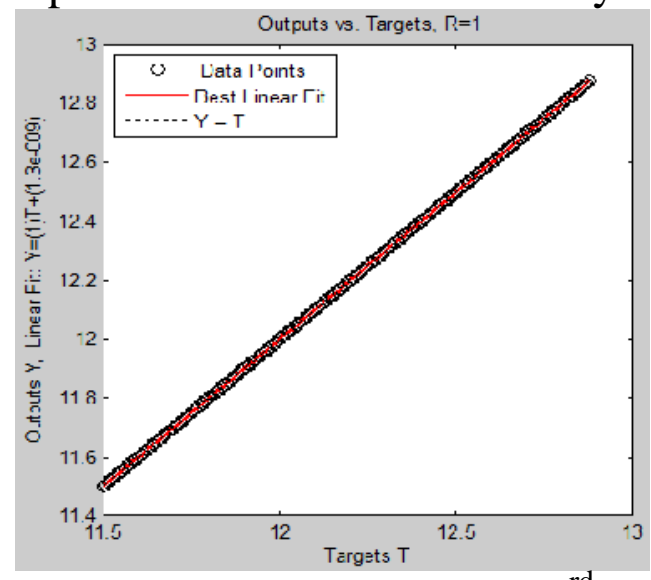

Fig. 29. Output VS Target for $3^{\text {rd }}$ Model 


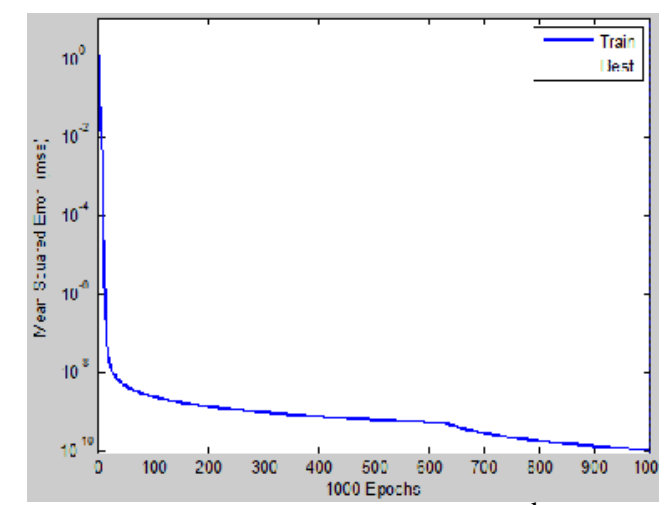

Fig. 30. Performance for $3^{\text {rd }}$ Model

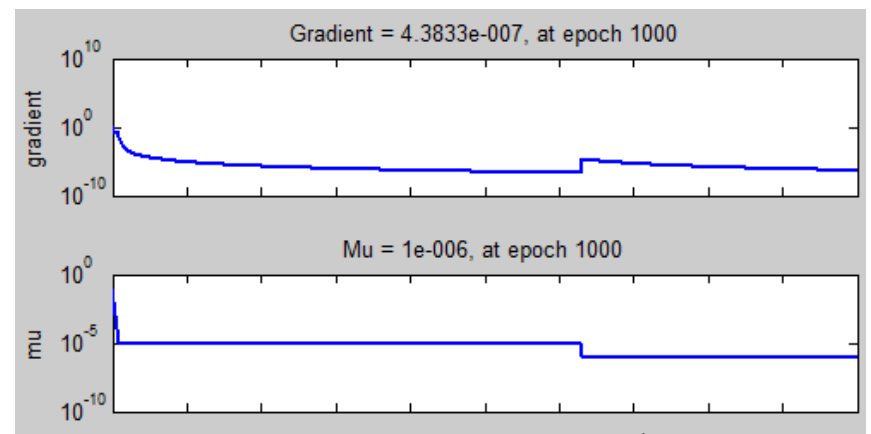

Fig. 31. Training state for $3^{\text {rd }}$ Model

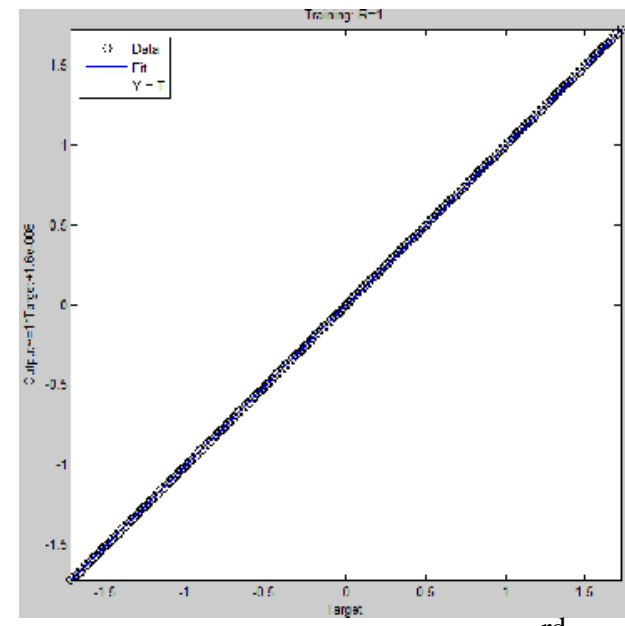

Fig. 32. Regression $(R=1)$ for $3^{\text {rd }}$ Model

The model algebraic equation is deduced as the following:

$$
\begin{aligned}
& \mathrm{E} 1=-0.2258 \mathrm{CA}_{\mathrm{n}}+0.0597 \mathrm{Time}_{\mathrm{n}}+0.9686 \mathrm{SOC}_{\mathrm{n}}-0.3687 \mathrm{~V}_{\mathrm{btdchn}}+1.2562 \mathrm{I}_{\mathrm{bn}}+0.9972 \\
& \mathrm{~F} 1=1 /(1+\exp (-\mathrm{E} 1)) \\
& \mathrm{E} 2=-0.0009 \mathrm{CA}_{\mathrm{n}}+0.0002 \mathrm{Time}_{\mathrm{n}}+0.0792 \mathrm{SOC}_{\mathrm{n}}-0.0013 \mathrm{~V}_{\mathrm{btdchn}}+0.0065 \mathrm{I}_{\mathrm{bn}}-0.1205 \\
& \mathrm{~F} 2=1 /(1+\exp (-\mathrm{E} 2)) \\
& \mathrm{E} 3=-0.0629 \mathrm{CA}_{\mathrm{n}}+0.0183 \text { Time }_{\mathrm{n}}+0.4427 \mathrm{SOC}_{\mathrm{n}}-0.1598 \mathrm{~V}_{\mathrm{btdchn}}+0.5258 \mathrm{I}_{\mathrm{bn}}-1.4344
\end{aligned}
$$




$$
\begin{aligned}
& \mathrm{F} 3=1 /(1+\exp (-\mathrm{E} 3)) \\
& \mathrm{E}_{\mathrm{bn}}=-0.1227 \mathrm{~F} 1+53.8343 \mathrm{~F} 2-0.6730 \mathrm{~F} 3-25.0794
\end{aligned}
$$

The un- normalized out put

$$
\mathrm{E}_{\mathrm{b}}=0.3990 \mathrm{E}_{\mathrm{bn}}+12.1875
$$

\subsection{Charging Resistance $\boldsymbol{R}_{\text {ch }}$ Model}

The forth model output is: Charging Resistance $\mathrm{R}_{\mathrm{ch}}$ range, with ranges of Battery Characteristics as inputs: Capacity Rate CA, State of Charge SOC, Time, Voltage $\mathrm{V}_{\text {bt_charging, and Current }} \mathrm{I}_{\mathrm{b}}$. The model here implemented with two layers, one hidden with $\log$-sig function and 3 neurons; second layer is with pure-line function with 1 neuron. Comparisons between the output and target, Performance, Training state, and Regression for $4^{\text {th }}$ Model are presented to show the validity of the model.

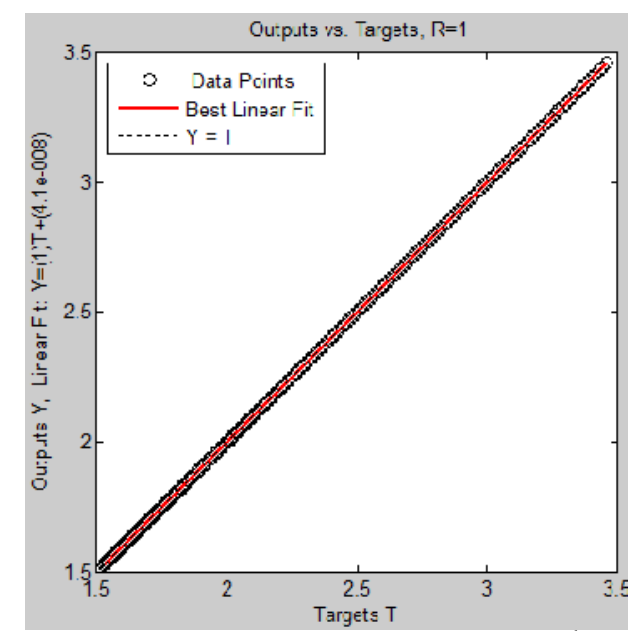

Fig. 33. Output VS Target for $4^{\text {th }}$ Model

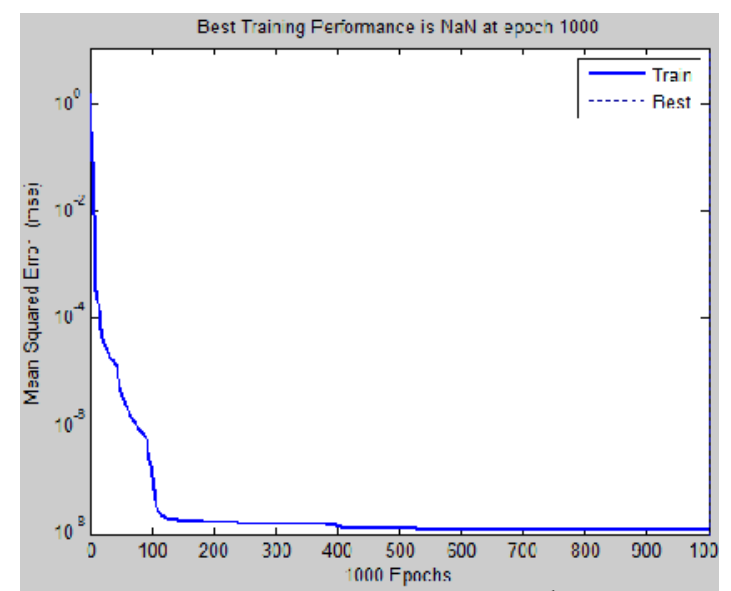

Fig. 34. Performance for $4^{\text {th }}$ Model 


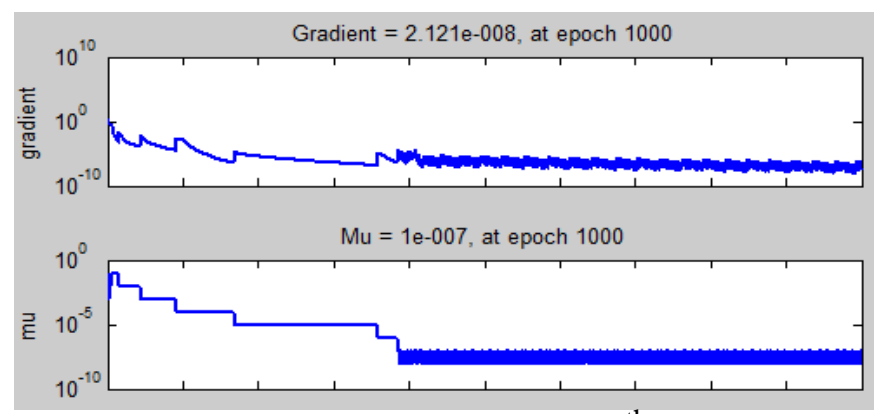

Fig. 35. Training state for $4^{\text {th }}$ Model

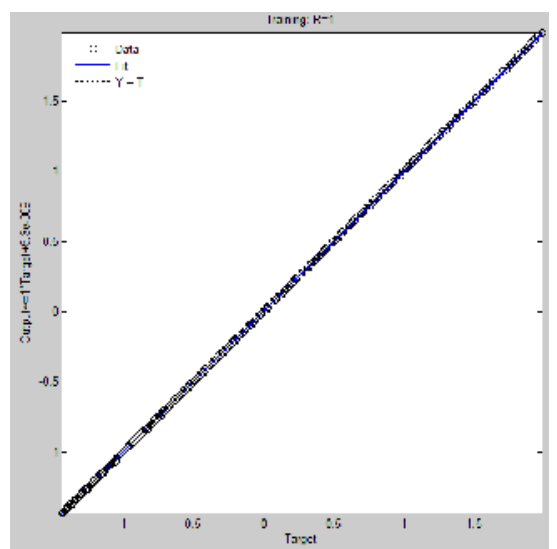

Fig. 36. Regression $(\mathrm{R}=1)$ for $4^{\text {th }}$ Model

$$
\mathrm{V}_{\mathrm{btchn}}=\left(\mathrm{V}_{\mathrm{btdch}}-13.0038\right) /(1.1591)
$$

Eq. (31) presents normalized charging voltage to be used with the other normalized inputs used before for the rest of ANN models. The model algebraic equation is deduced as the following:

$$
\begin{gathered}
\mathrm{E} 1=12.3025 \mathrm{CA}_{\mathrm{n}}+2.4585 \mathrm{Time}_{\mathrm{n}}-2.3909 \mathrm{SOC}_{\mathrm{n}}+23.6540 \mathrm{~V}_{\mathrm{btchn}}-26.6415 \mathrm{I}_{\mathrm{bn}}+3.2817 \\
\mathrm{~F} 1=1 /(1+\exp (-\mathrm{E} 1)) \\
\mathrm{E} 2=-0.0005 \mathrm{CA}_{\mathrm{n}}-0.00004 \mathrm{Time}_{\mathrm{n}}-0.6134 \mathrm{SOC}_{\mathrm{n}}-0.0001 \mathrm{~V}_{\mathrm{btchn}}+ \\
\mathrm{F} 2=1 /(1+\exp (-\mathrm{E} 2)) \\
\mathrm{E} 3=0.0002 \mathrm{I}_{\mathrm{bn}}+1.9592 \\
\mathrm{CA} \mathrm{n}_{\mathrm{n}}+0.0002 \mathrm{Time}_{\mathrm{n}}-0.8451 \mathrm{SOC}_{\mathrm{n}}+0.0004 \mathrm{~V}_{\mathrm{btchn}}+0.0015 \mathrm{I}_{\mathrm{bn}}-0.3703 \\
\mathrm{~F} 3=1 /(1+\exp (-\mathrm{E} 3)) \\
\mathrm{R}_{\text {CHRGEn }}=-0.0003 \mathrm{~F} 1-10.4831 \mathrm{~F} 2-1.4530 \mathrm{~F} 3+9.6429 \\
\text { The un- normalized out put } \\
\mathrm{R}_{\text {CHRGE }}=0.5651 \mathrm{R}_{\text {CHRGEn }}+2.3394
\end{gathered}
$$

\section{Conclusion}

Due the importance of Lead-acid battery as storage unit in many applications especially for green energy, this paper is proposed. New flexible and efficient modeling method is introduced. First, a $12 \mathrm{~V}, 4 \mathrm{Ah}$ lead-acid battery is modeled. All the parameters of the battery model are identified as functions of State Of Charge (SOC) of 
the battery mainly, using curve fitting technique, and the NP4-12 YUASA battery manufacturer's data sheet for all capacity rates and verified to get good matching with the real characteristics. Second, a neural network based learning system method with back-probagation technique has been proposed for parameters estimation as efficient facility with the aid of MATLAB toolbox. These Models help any user, designer or researchers to easily identify parameters and characteristics for this battery type with capacity ranges $0.05,0.1,0.2,0.4,0.6,1,2$ and $3 \mathrm{CA}$. The model parameters and characteristics are well depicted in the form of 3D figures. The ANN technique is used to estimate Thevenin Electric Model' parameters in the form of ANN models with their algebraic equations. The proposed outputs for the models are: Discharging Resistance, Shunt Resistance, Back e.m.f. and Charging Resistance; each one is deduced with Battery Characteristics as inputs for every previous outputs: Capacity Rate, State of Charge, Time, Voltage, and Current. ANN models are created with suitable numbers of layers and neurons, which trained, simulated, checked and their algebraic equations are concluded accurately with excellent regression constant for all almost 1 . The neural models have the ability to predict values in - between learning values, also make interpolation between learning curves data at various characteristics. Finally, deduction of algebraic nonlinear function which, connects between inputs and outputs for neural networks are presented, to can aid any designer without the need of training the neural network each time. The validity of this algebraic function is achieved from comparison between target and output moreover, the excellent regression factors achieved.

\section{References}

1. John B., Aiming Z., Bo S., Kristen H., "Evaluating the potential of small scale renewable energy options to meet rural livelihoods: A GIS and life-cycle costbased assessment of western china's options", Elsevier energy policy, 35. 2007, pp. 4391-4401.

2. IEA, "Lead-acid battery guide for stand-alone photovoltaic systems", IEA Task III, Report IEA-PVPS3-06 1999.

3. Derek P.and Frank C.W., "Industrial electrochemistry 2nd edition', Chapman and Hall, New York, 1990 .

4. Markus R., Hans-Peter B., Schneidegger R., "Minimizing the environmental impact of large-scale rural PV", Renewable energy world, James and James(science publishers) Ltd London, vol4, number1, 2001, pp. 47-59.

5. Sathiakumar S. "An Investigation on the suitable battery system for marine Applications", School of Electrical and Information engineering, University of Sydney. Sydney, 2006.

6. Reid C.E, "Chemical Thermodynamics", McGraw Hill Series in Advanced Chemistry. McGraw Hill Singapore, 1990. 
7. Sorensen B. "Renewable energy. Its physics, engineering ,use, environmental impacts , economy and planning aspects", 3rd edition. Elsevier science, Amsterdam, 2004.

8. Yuasa Battery-Europe. Endurance Battery Manual, 1998.

9. Battery characteristics: Teaching and Learning Packages. Department of Materials Science and Metallurgy, University of Cambridge. Dissemination of IT for the Promotion of Materials Science; http://www.doitpoms.ac.uk/tlplib/batteries/index.php

10.Power-sonic corporation, " Sealed Lead-Acid Batteries", Technical Handbook, 2008.

11.Panasonic Ltd, "Overview of Lithium-Ion Batteries", Technical Manual, 2007.

12.Sadli, I.; Marie-Joseph, I.; Primerose, A.; Clergeot, H., "New battery dynamic model: Application to lead-acid battery", The 2nd International Conference on Computer and Automation Engineering (ICCAE), 26-28 Feb. 2010, Vol. 5, pp. $140-145$.

13.Hartmann, L.V.; Correa, M.; Lima, A.M.N., Leao, J.F.A., " Lead-acid battery modeling and state of charge monitoring", Applied Power Electronics Conference and Exposition (APEC), 2010 Twenty-Fifth Annual IEEE, 21-25 Feb. 2010, pp. $239-243$.

14.Bambang Sri Kaloko, Soebagio and Mauridhi Hery Purnomo. Estimation of Residual Capacity of Lead Acid Battery using RBF Model. IJCA Special Issue on Artificial Intelligence Techniques - Novel Approaches \& Practical Applications (3):12-17, 2011. Published by Foundation of Computer Science.

15.Ganesan, A. and Sundaram, S., "A Heuristic Algorithm for Determining State of Charge of a Lead Acid Battery for Small Engine Applications," SAE Technical Paper 2012-32-0082, 2012, doi:10.4271/2012-32-0082.

16.Le, D. and Sisk, B., "Lead-Acid State of Charge Estimation for Start-Stop Applications," SAE Technical Paper 2013-01-1532, 2013, doi:10.4271/2013-011532.

17.Ceraolo, M., "New dynamical models of lead-acid batteries", IEEE Transactions on Power Systems, Vol. 15, Issue 4, Nov. 2000, pp. 1184-1190.

18. Salameh Z.M., Casacca M.A., and Lynch W.A., "A mathematical model for leadacid batteries", IEEE Transactions on Energy Conversion, Vol. 7, No. 1, 1992, pp. 93-98.

19.Matthias Dürr, Andrew Crudena, Sinclair Gaira and J.R. McDonalda, "Dynamic model of a lead acid battery for use in a domestic fuel cell system" , Journal of Power Sources, Vol. 161, Issue 2, October 2006, pp. 1400-1411.

20.Jantharamin N., Zhang, L.,"A new dynamic model for lead-acid batteries", 4th IET Conference on Power Electronics, Machines and Drives, April 2008, pp. 8690. 
21.Chan H.L., Sutanto D., "A new battery model for use with battery energy storage systems and electric vehicles power systems", IEEE Power Engineering Society Winter Meeting, Vol. 1, pp. 470-475, 2000.

22.NP valve regulated lead acid battery manual, Yuasa Battery Sale (UK) Ltd., 1991

23. Adel El Shahat, Book "PM Synchronous Machine New Aspects; Modeling, control, and design", ISBN 978-3-659-25359-1, LAP Lambert Academic Publishing, Germany, 2012.

24.Adel El Shahat, "DC-DC Converter Duty Cycle ANN Estimation for DG Applications", Journal of Electrical Systems (JES), ISSN 1112-5209; Vol. 9, Issue 1, March 2013.

25.Adel El Shahat and Adel T. Y. Tawfik, "A Neuro-Modelling for New Biological Technique of Water Pollution Control", Journal of Arab Research Institute for Science \& Engineering, ISSN 1994-3253; Second Quarter 2010 (April-June).

26. Adel El Shahat, and Hamed El Shewy, "High Fundamental Frequency PM Synchronous Motor Design Neural Regression Function", Journal of Electrical Engineering, ISSN 1582-4594; Article 10.1.14, Edition 1, March, Vol. 10 / 2010.

27.A. El Shahat, and H. El Shewy, "PM Synchronous Motor Control Strategies with Their Neural Network Regression Functions", Journal of Electrical Systems (JES), ISSN 1112-5209; Vol. 5, Issue 4, Dec. 2009.

28. Adel El Shahat, "Photovoltaic Power System Simulation for Micro - Grid Distribution Generation", 8th International Conference on Electrical Engineering, 29-31 May, 2012, Military Technical College, Egypt; EE137, ICEENG 2012.

29.Adel El Shahat, and Hamed El Shewy, "High Speed Synchronous Motor Basic Sizing Neural Function for Renewable Energy Applications", MDGEN05, The International Conference on Millennium Development Goals (MDG): Role of ICT and other technologies December 27 - 29, 2009 in Chennai, India.

30.El Shahat, H. El Shewy, "Neural Unit for PM Synchronous Machine Performance Improvement used for Renewable Energy", Paper Ref.: 910, Global Conference on Renewable and Energy Efficiency for Desert Regions (GCREEDER2009), Amman, Jordan.

31.A.Y. Tawfik and A. El Shahat, "Speed Sensorless Neural Controller for Induction Motor Efficiency Optimization", 1st International Conference on Advanced Control Circuits and Systems (ACCS'05), ACCS Catalog No: 080610 M 05, ISBN: 0 - 146 - 6310 - 7933 - 2, March 6 - 10, 2005, Cairo, Egypt.

32.H. El Shewy, A.Y. Tawfik and A. El Shahat, "Neural Model of 3 phase Induction Motor", 1st International Conference on Advanced Control Circuits and Systems (ACCS'05), ACCS Catalog No: 080610 M 05, ISBN: 0 - 145 - $6310-7933$ - 2, March 6 - 10, 2005, Cairo, Egypt. 